\title{
Temporal Lobectomy with Amygdalectomy and Minimal Hippocampal Resection: Review of 100 Cases
}

\author{
William Feindel and Theodore Rasmussen
}

\begin{abstract}
The evidence for the role of the amygdala in temporal lobe seizures is supported by this follow-up (2-20 years) of 100 patients who were treated surgically by excision of the antero-lateral temporal cortex, most or all of the amygdala and minimal resection of the hippocampus. The findings showed 53 patients seizure-free or with rare or occasional seizures, 10 patients with marked seizure reduction and 37 with moderate or less reduction of seizures. The results are the same as in another 100 patients where, in addition, half or more of the hippocampus was resected.
\end{abstract}

RÉSUMÉ: Lobectomie temporale avec amygdalectomie et résection minimale de l'hippocampe: revue de 100 cas. Le rôle crucial joué par l'amygdale dans les crises épileptiques temporales est mis en évidence par cette étude portant sur 100 patients, dont le suivi s'échelonne entre 2 et 20 ans, et ayant subi une excision du cortex temporal antéro-latéral avec, en plus, une exérèse (totale ou quasi totale) de l'amygdale et une résection minimale de l'hippocampe. Cinquante-trois patients ont complètement cessé d'avoir des crises ou n'en ont que rarement; 10 patients ont obtenu une réduction marquée et 37 ont noté une diminution modérée ou légère de la fréquence de leurs crises. Nos résultats sont comparables à ceux d'une autre étude portant sur 100 patients, chez qui, en plus, la moitié ou plus de l'hippocampe a été réséquée.

Can. J. Neurol. Sci. 1991; 18: 603-605

\section{Amygdaloid SEIZURES}

From earlier observations it was evident that the amygdala plays a critical role as a generator of seizures in many patients with temporal lobe epilepsy associated with automatism and amnesia. ${ }^{1}$ It therefore seemed logical to adopt a surgical approach that included the amygdala in the temporal lobe resection for the control of seizures. ${ }^{2}$

These early findings on the amygdala have been substantiated by further results from ECG, direct stimulation and recording during operation, as well as from neuropathological and neuropsychological studies.

Amygdaloid seizures can be characterized by the following features:

1. Auras of sensory, autonomic or experiential type. The most frequent include cephalic or bodily sensation, conscious confusion, déjà vu, fear and hallucinations; 2. Automatism; 3. Post-ictal confusion and amnesia; 4. Mesial temporal EEG focus; 5. At operation maximal ECG spiking recorded from the amygdala; 6 . Auras, after-discharge and sometimes seizures evoked from stimulation of the amygdala; 7. Structural lesions or sclerosis of amygdala shown on MRI and histopathology; 8. Arrest or reduction of seizures after temporal lobectomy with maximal removal of amygdala and minimal resection of anterior hippocampus.

\section{Anatomy and Stimulation Responses of the Amygdala}

Several important points may be emphasized. First, each amygdala has powerful reciprocal anatomical connections with mid-line structures, the brainstem, and widespread areas of cortex. They have, in addition, strong connections to each other and thus to the opposite hemisphere by way of the stria terminalis, the anterior commissure and possibly by a neuronal network extending medially directly through the substantia innominata. ${ }^{2}$

In patients during operation, the amygdala rather than the hippocampus or the surrounding temporal cortex was most commonly implicated in the production of these features of automatism with amnesia. ${ }^{3.4}$ These observations, repeated many times in the operating room, were further extended by pre-operative depth electrode studies of these mesial temporal structures by Gloor, Olivier et al. ${ }^{5}$ who showed that the full range of hallucinatory phenomena obtained previously from stimulation of lateral temporal cortex could also be produced from the amygdala, and, less commonly, from the anterior hippocampus.

\section{Pathology of the Amygdala}

Two further developments in the past five years have supported strongly the hypothesis that the amygdala plays a crucial role as the pathological generator of ictal activity in temporal 
lobe seizures. First, careful resection of the amygdaloid tissue for microscopic studies has shown in a majority of patients, sclerosis, astrocytic gliosis and neuronal loss. Secondly, the advent of magnetic resonance imaging has detected a larger number of small benign lesions, $30 \%$ of which have not been visible on CT examination. MRI has identified for the first time this "sclerosis" in the mesial temporal region which can be confined to the region of the amygdala and the anterior hippocampus. ${ }^{6}$ We are now correlating the features of seizure pattern, EEG localization, MRI findings, cortiographic findings at operation, and pathology with the longer term follow-up in seizure control and neuropsychological evaluation. ${ }^{7}$ MRI provides a more objective means of evaluating cases for operation, for documenting precisely the anatomical extent of the surgical resection and for comparison with the pathological changes in the resected amygdala. Reasons for success and failure of surgical treatment should be more clearly deduced than in the past. 8 Variations in the surgical approaches and techniques as well as the extent and type of resections among different surgical centers can now be more critically analyzed.

\section{EXCISION OF THE AMYGDALA}

Resection of the amygdala is exacting, because of its intricate overlap with the anterior part of the hippocampus, its contiguity in the uncus to the subiculum and its superior extension juxtaposing the substantia innominata. But with microsurgical techniques it is possible to carry out an almost anatomically complete resection of this structure with minimal removal of the hippocampus itself or of the hippocampal gyrus.

The surgical approach involves first the removal of the anterior part of the temporal lobe by dissecting it off from the mesial part of the lobe. Deep in the Sylvian fissure where one can identify the middle cerebral artery, the anterior and lateral cortex can then be excised by dividing the white matter of the temporal stem. This does not include the amygdala. At the next stage, deeper dissection between the stem of the middle cerebral artery and the tip of the opened temporal hom of the ventricle gives clear exposure of the anterior part of the hippocampus and helps to define the anatomical limits of the amygdala. The line of resection then includes the amygdala and the uncus extending posteriorly but only a minimal part of the hippocampus (Figure 1). The amygdala caps the temporal horn of the ventricle. Its mesial and superior portion extends behind and above the anterior end of the hippocampus.

Surgeons reporting that at re-operation, additional resection of hippocampus may turn a clinical failure into success in some instances, may well be converting an inadequate removal of the amygdala into a more nearly complete excision.

In the follow-up series of patients with no or minimal hippocampal resection, there were 100 individuals operated on between 1961 and 1980 with a range of 2 to 20 year follow-up, and a median of 12 years (Table 1). The results show that $63 \%$ had satisfactory post-operative results, either being seizure free, or with a marked reduction of seizure frequency. This is the same rate of success as in the 100 patients over the same period of follow-up who had moderate to large removals of hippocampus along with amygdalectomy. ${ }^{9}$ This figure compares favorably to the total MNI series of over 1,000 patients with temporal lobe epilepsy operated on between 1928 and 1980 with a success rate of $63 \%$ as judged by these same criteria. 10
Thus, in this study series, excision of the anterior temporal lobe with complete removal of the amygdala but with minimal hippocampal removal yields the same benefit of seizure control as a much larger hippocampal resection. " A substantial advantage of this pattern of excision is the sparing of the hippocampus and hippocampal gyrus and the resultant protection of the associated memory function, as detailed in the postoperative studies of these cases by Milner and Associates. ${ }^{12,13}$

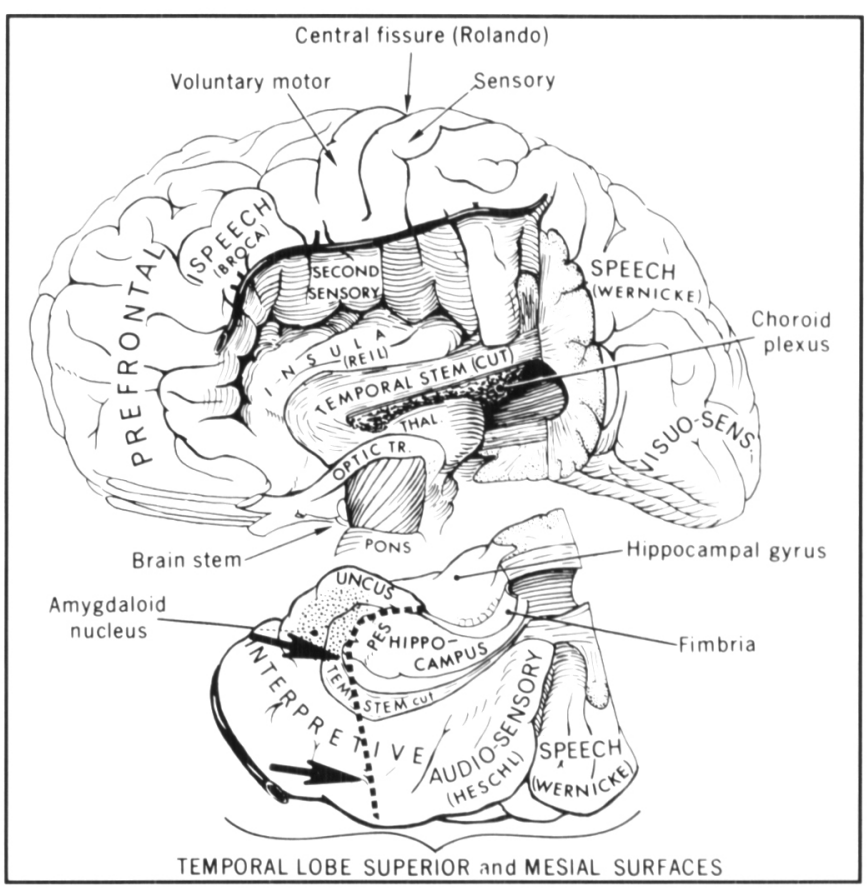

Figure 1. - Drawing of anatomical dissection of the temporal lobe to show the line of surgical resection (arrow) that includes the anterior polar cortex and the amygdala, but with minimal removal of the hippocampus (modified from Feindel and Penfield, 1954).

Table 1: Temporal Lobectomy Non-Tumoral Series. Patients with No or Minimal Hippocampal Excision. Follow-up Results on 100 Patients Who Had Anterior Temporal Lobectomy with Amygdalectomy but Minimal Hippocampal Resection.

\begin{tabular}{|c|c|c|c|c|}
\hline \multirow{2}{*}{$\begin{array}{c}\begin{array}{c}\text { Follow-up } \\
\text { Classification }\end{array} \\
0\end{array}$} & \multicolumn{4}{|c|}{ Operated upon 1961-1980 } \\
\hline & $\begin{array}{c}\text { Seizure free } \\
\text { since discharge }\end{array}$ & $21 \mathrm{pts}$. & & \\
\hline 1 & $\begin{array}{c}\text { Became seizure } \\
\text { free after some } \\
\text { early attacks }\end{array}$ & 17 pts. & 38 pts. & $\begin{array}{c}63 \text { pts. } \\
2-24 \text { yrs. }\end{array}$ \\
\hline$\overline{2}^{-} \cdot$ & $\begin{array}{l}\text { Seizure free } 3 \text { or } \\
\text { more years, then rare } \\
\text { or occasional attacks }\end{array}$ & $15 \mathrm{pts}$ & 25 pts. & $\begin{array}{c}\text { follow-up } \\
\text { (median } \\
12 \text { yrs.) }\end{array}$ \\
\hline 3 & $\begin{array}{l}\text { Marked reduction } \\
\text { of seizure tendency }\end{array}$ & 10 pts. & & \\
\hline 4 & $\begin{array}{l}\text { Moderate or less } \\
\text { reduction of } \\
\text { seizure tendency }\end{array}$ & 37 pts. & & \\
\hline
\end{tabular}

Total 100 pts. 


\section{REFERENCES}

1. Feindel W, Penfield W, Jasper H. Localization of epileptic discharge in temporal lobe automatism. Trans Am Neurol Assoc 1952; 14-17.

2. Feindel W, Penfield W. Localization of discharge in temporal lobe automatism. Arch Neurol Psychiatry 1954; 72: 605-630.

3. Feindel $W$. Response patterns elicited from the amygdala and deep temporoinsullar cortex. In: Sheer, D.E. ed. Electrical Stimulation of the Brain. Austin: University of Texas Press 1961: 519-532.

4. Feindel W. Temporal lobe seizures. In: Magnus O. and Lorentz A.M. de Haas, eds. Handbook of Clinical Neurology. Amsterdam: North-Holland Publishing 1974; 87-106.

5. Gloor $P$, Oliver A, Quesney LF, et al. The role of limbic system in experiential phenomena of temporal lobe epilepsy. Ann Neurol 1982; 12: 129-144.

6. Kuzniecky R, de la Sayette V, Ethier R, et al. Magnetic resonance imaging in temporal lobe epilepsy: pathology correlations. Ann Neurol 1987; 22: 341-347.

7. Feindel W, Robitaille Y, Tampieri D, et al. MRI findings in temporal lobe epilepsy: correlation with surgical pathology (this supplement).
8. Feindel W. Factors contributing to the success or failure of surgical intervention for epilepsy. In: Purpura DP, Penry JK, Walter RD, eds. Advances in Neurology. New York: Raven Press 1975; 281 298.

9. Rasmussen T, Feindel W. Temporal lobectomy with major hippocampectomy: review of 100 cases (this supplement).

10. Rasmussen T. Surgical treatment of complex partial seizures: results, lessons and problems. In: Epilepsia. 1983; 24 (suppl. 1): S-65-S76.

11. Leonard G. Temporal lobe surgery for epilepsy: neuropsychological variables related to seizure outcome (this supplement).

12. Milner B. Clues to the cerebral organization of memory. In: Buser P.A., Rougeul-Buser, A. eds. Cerebral Correlates of Conscious Experience. INSERM Symposium No. 6. Amsterdam: Elsevier/North Holland. 1978; 139-153.

13. Smith $\mathrm{ML}$, Milner $\mathrm{B}$. The role of the right hippocampus in the recall of spatial location. Neuropsychologia. 1981; 19: 781-795. 